\title{
Intradialytic parenteral nutrition: comparison of olive oil versus soybean oil- based lipid emulsions
}

\author{
Noël J. M. Cano ${ }^{1 *}$, Yannick Saingra ${ }^{1}$, Anne-Marie Dupuy ${ }^{2}$, Anne-Marie Lorec-Penet ${ }^{3}$, Henri Portugal $^{3}$, \\ Denis Lairon ${ }^{4}$, Jean-Paul Cristol ${ }^{2}$, Adrien Come ${ }^{5}$, Alexia Le Brun ${ }^{5}$, Philippe Atlan ${ }^{5}$ and Xavier M. Leverve ${ }^{6}$ \\ ${ }^{1}$ Service d'Hépatogastroentérologie et Nutrition, Clinique Résidence du Parc, Rue Gaston Berger, 13362, Marseille cedex 10, \\ France \\ ${ }^{2}$ Laboratorie de Biochimie, Hopital hapeyronie, 371 Avenue Doyen Gaston Gvaud, 34295 Montpellier, France \\ ${ }^{3}$ Laboratoire central, CHU Sainte-Marguerite, Boulerard Sainte-Marguerite, 13009 Marseilles, France \\ ${ }^{4}$ UMR 476-INSERM/1260-INRA, Faculté de Médecine, 27 Boulevard Jean Moulin, 13385 Marseille Cedex 5, France \\ ${ }^{5}$ Baxter SAS, 6 Avenue Louis Pasteur, BP 56, 7811 Maurepas, Cedex France \\ ${ }^{6}$ INSERM-E0221, Bioénergétique Fondamentale et Appliquée, Université Joseph Fourier - BP 53XF, 38041 Grenoble, Cedex \\ France
}

(Received 18 April 2005 - Revised 22 July 2005 - Accepted 3 August 2005)

\begin{abstract}
Lipid, oxidative and inflammatory parameters are frequently altered in dialysis patients and may be worsened by intravenous lipid emulsions (ILE). We assessed the efficacy and tolerance of olive as compared with standard soybean oil-based ILE during intradialytic parenteral nutrition (IDPN). IDPN mixtures containing amino acids, glucose, and either olive oil (OO group, $n$ 17) or soybean oil-based ILE (SO group, $n$ 18) were administered in a 5-week randomized, double-blind study. On days 0 and 35, patients' nutritional status was assessed by BMI, normalized protein catabolic rate, predialytic creatinine, serum albumin and transthyretin; lipid metabolism by plasma LDL- and HDL-cholesterol, triacylglycerols, phospholipids, apo A-I, A-II, B, C-II, C-III, E and lipoprotein (a); oxidative status by $\alpha$-tocopherol, retinol, selenium, glutathione peroxidase, malondialdehyde and advanced oxidized protein products; inflammatory status by serum C-reactive protein, orosomucoid, IL-2 and IL-6. No serious adverse event was observed. Significant changes were observed from day 0 to day $35(P<0 \cdot 05)$ : nutritional criteria improved (albumin in OO; albumin, transthyretin and creatinine in SO); LDL-cholesterol, apo B, C-II, C-III and apo A-I/A-II ratio increased in both groups. HDL-cholesterol decreased in OO; apo E increased and lipoprotein (a) decreased in SO; $\alpha$-tocopherol/cholesterol ratio increased in OO; malondialdehyde decreased in both groups; IL-2 increased in both groups. The between-group comparison only showed the following differences: $\alpha$-tocopherol/cholesterol increased in OO; lipoprotein (a) decreased in SO. From these data, it was concluded that OO- and SO-based IDPNs similarly improved nutritional status and influenced plasma lipid, oxidative, inflammatory and immune parameters.
\end{abstract}

Haemodialysis: Intradialytic parenteral nutrition: Fat emulsions: Olive oil

In spite of the improvement of dialysis techniques, haemodialysis patients are still characterized by mortality rates of $10 \%$ in Europe (Combe et al. 2001; Held et al. 1990). In this setting, malnutrition is recognized as an independent determinant of both hospitalizations (Ikizler et al. 1999) and mortality (Cano et al. 1987; Combe et al. 2001; Owen et al. 1993). Intradialytic parenteral nutrition (IDPN) is a cyclic parenteral nutrition provided during dialysis sessions through the venous way of the extracorporeal circuit. IDPN was reported to improve nutritional status in numerous studies (Blondin \& Ryan, 1999; Heidland \& Kult, 1975; Madigan et al. 1990; Mortelmans et al. 1999; Schulman et al. 1993; Smolle et al. 1995), non-controlled comparative studies (Capelli et al. 1994; Chertow et al. 1994; Hiroshige et al. 1998; Oguz et al. 2001; Piraino et al. 1981) and two randomized trials (Cano et al. 1990; Navarro et al. 2000). Three non-controlled series suggested that IDPN improves patient outcome (Capelli et al. 1994; Chertow et al. 1994; Foulks, 1994). Intravenous lipid emulsions (ILE) have been included in IDPN since 1990 (Blondin \& Ryan, 1999; Cano et al. 1990; Capelli et al. 1994; Foulks, 1994; Hiroshige et al. 1998; Madigan et al. 1990; Mortelmans et al. 1999; Snyder et al. 1991). During IDPN, the utilization of a mixed energy supply, associating ILEs together with glucose, instead of a high glucose supply, is supported by several arguments: fat oxidation is increased in haemodialysis patients (Schneeweiss et al. 1990); insulin resistance is quite constant (DeFronzo et al. 1981); ILEs make it possible to reduce the nutritive mixture osmolarity while maintaining a high energy load; the reduction of glucose load may decrease the risk of post-dialysis hypoglycaemia (Wolfson \& Foulks, 1996); essential fatty acid deficiencies have been

Abbreviations: IDPN, intradialytic parenteral nutrition; ILE, intravenous lipid emulsions; nPCR, normalized protein catabolism rates; OO, olive oil group; SO, soybean oil group.

* Corresponding author: Dr Noël Cano, fax +334918388 38, email njm.cano@wanadoo.fr 
reported in malnourished haemodialysis patients (Dasgupta et al. 1990). However, malnourished haemodialysis patients are characterized by decreased plasma lipid clearance (Attman et al. 2003), and frequently exhibit abnormal oxidative (Locatelli et al. 2003), inflammatory and immune status (Ikizler et al. 1999; Kaysen, 2001; Qureshi et al. 2002). Lipid infusion during IDPN may interfere with these metabolic and immune abnormalities.

Until now, only standard ILEs prepared from soybean oil and composed of long-chain triacylglycerols, containing $62 \%$ PUFA, have been used during IDPN. More recently, a new ILE has been developed from a mixture of $80 \%$ olive oil and $20 \%$ soybean oil, and contains only long-chain triacylglycerols, with a low proportion of PUFA and $60 \%$ MUFA. Previous clinical studies showed the efficacy and safety of this ILE in non-renal paediatric and adult malnourished patients (Goulet et al. 1999). Such an olive oil-based ILE may offer several advantages such as a reduction of oxidative and inflammatory effects of the infusion of soybean-based ILE (Goulet et al. 1999; Granato et al. 2000; Moussa et al. 2000).

The aim of the present study was to assess, in malnourished haemodialysis patients, the efficacy and safety of this new olive oil-based ILE as compared with a standard soybean oil-based ILE. The effects of the two ILE on nutritional status, plasma lipids, inflammatory, immune and oxidative parameters were measured.

\section{Methods}

\section{Patients}

Out-patients treated by routine haemodialysis for more than 6 months in the Clinique Résidence du Parc haemodialysis centre were asked to participate in the study when they presented with three of the five following criteria of malnutrition: BMI $<20 \mathrm{~kg} / \mathrm{m}^{2}$, weight loss $>10 \%$ within 6 months, serum albumin $<35 \mathrm{~g} / \mathrm{l}$, transthyretin (prealbumin) $<300 \mathrm{mg} / \mathrm{l}$, normalized protein catabolism rates $(\mathrm{nPCR})<1 \mathrm{~g} / \mathrm{kg}$ per $\mathrm{d}$. Exclusion criteria were: age $>80$ or $<18$, history of hospitalization during the last 5 weeks, fat emulsion infusion during the last 2 weeks, associated disease compromising the 6 -month survival, weekly dialysis time $<12 \mathrm{~h}$, severe inflammation as attested by serum C-reactive protein $>20 \mathrm{mg} / \mathrm{l}$, liver disease as documented by serum ALAT $>2$ normal range value, bilirubin $>2$ normal range value or prothrombin time $<70 \%$ of normal values, plasma triacylglycerols $>2 \mathrm{~g} / \mathrm{l}$.

Among the 320 patients treated in the haemodialysis centre, forty-seven patients fulfilled the inclusion criteria. Forty-one of them agreed to participate in the study and were randomized into two groups: twenty-one were assigned to IDPN containing the olive oil-based emulsion (Clinoleic ${ }^{\circledR}$; Baxter, Maurepas, France) and twenty to IDPN containing the soybean oil-based emulsion (Ivelip ${ }^{\circledR}$; Baxter). These forty-one patients were considered for the safety study. Six patients were removed during the treatment for consent withdrawal (see later). Thus, thirty-five patients completed the study and were analysed in a per protocol fashion in order to compare the effects of the IDPN on nutritional, lipid metabolism, oxidative, inflammatory and immune status: Group OO ( $n$ 17, seven males, ten females, aged 73.2 (SEM 3.0) years) received the IDPN containing the olive oil-based emulsion, and group
SO ( $n$ 18, eight males, ten females, aged 66.5 (SEM 3.4)) received the IDPN containing the soybean oil-based emulsion. At inclusion, the two groups were not different for age, sex and dialysis history (mean years: OO, 5.74 (SEM 1.47); SO, 6.64 (SEM 1.71)). Eight patients in $\mathrm{OO}$ and four in SO were diabetics. Three patients in each group received 3-hydroxy3-methylglutaryl-CoA reductase inhibitors prior to inclusion in the trial. These therapies were not modified during the experimental period. No patient received $n-3$ fatty acid or vitamin $\mathrm{E}$ or other medications known to modify lipid or oxidative stress profile before or during the experimental period.

\section{Study design}

This monocentre study was performed as a prospective, controlled, double-blind and randomized trial. IDPN bags were supplied by FASONUT (Montpellier, France) with either Clinoleic ${ }^{\circledR}$ or Ivelip ${ }^{\circledR}$ as ILE. Lipids were allocated to the patients by envelopes in a chronological order according to the randomization scheme. No stratification was applied. Then, FASONUT labelled the bags for the double-blind clinical study needs. After inclusion, patients were assigned to one of the two treatment groups for a period of 5 weeks. The two groups were treated in parallel during 5 weeks, i.e. fifteen dialysis sessions.

\section{Intradialytic parenteral nutrition}

IDPN mixtures were contained in 1-litre bags providing $50 \mathrm{~g}$ standard amino acids and 4184 non-protein $\mathrm{kJ}(1000 \mathrm{kcal})$ in the form of $125 \mathrm{~g}$ glucose and $50 \mathrm{~g}$ fat emulsion. The composition of fat emulsions is given in Table 1. During the first week, patients were given $8 \mathrm{ml} / \mathrm{kg}$ per IDPN. Then, they received $16 \mathrm{ml} / \mathrm{kg}$ per IDPN when body weight was $<60 \mathrm{~kg}$ and the full 1-litre bag when body weight was $\geq 60 \mathrm{~kg}$. IDPN was infused at a constant rate, $\leq 250 \mathrm{ml} / \mathrm{h}$, during the whole dialysis session and associated with a simultaneous haemofiltration of an equivalent volume. In order to compensate sodium losses due to haemofiltration, $4 \mathrm{~g}$ sodium chloride were added per litre of IDPN.

Table 1. Composition of fat emulsions ${ }^{\star}$

\begin{tabular}{|c|c|c|}
\hline & Clinoleic ${ }^{\circledR} 20 \%$ & Ivelip ${ }^{\circledR} 20 \%$ \\
\hline Soybean oil & $40 \mathrm{~g} / \mathrm{l}$ & $200 \mathrm{~g} / \mathrm{l}$ \\
\hline Olive oil & $160 \mathrm{~g} / \mathrm{l}$ & \\
\hline Egg phospholipids & $12 \mathrm{~g} / \mathrm{l}$ & $12 \mathrm{~g} / \mathrm{l}$ \\
\hline Glycerol & $22.5 \mathrm{~g} / \mathrm{l}$ & $25 \mathrm{~g} / \mathrm{l}$ \\
\hline PUFA & $20 \%$ & $60 \%$ \\
\hline$n-6$ fatty acids & $18 \%$ & $52 \%$ \\
\hline Linoleic acid & $18 \%$ & $52 \%$ \\
\hline$\gamma$-Linoleic acid & $<0.1 \%$ & $<0.1 \%$ \\
\hline$n-3$ fatty acids & $2 \cdot 2 \%$ & $8 \cdot 2 \%$ \\
\hline$\alpha$-Linolenic acid & $2 \%$ & $8 \%$ \\
\hline Eicosapentanoic acid & $<0.02 \%$ & $<0.02 \%$ \\
\hline Docosahexaenoic acid & $0.12 \%$ & $0.15 \%$ \\
\hline MUFA & $63 \%$ & $23 \%$ \\
\hline Saturated fatty acids & $17 \%$ & $17 \%$ \\
\hline$\alpha$-Tocopherol & $30 \mathrm{mg} / \mathrm{l}$ & $12 \mathrm{mg} / \mathrm{l}$ \\
\hline$\alpha$-Tocopherol/PUFA & $0.75 \mathrm{mg} / \mathrm{g}$ & $0.10 \mathrm{mg} / \mathrm{g}$ \\
\hline
\end{tabular}

*\% refers to percentage of total fatty acids on a per weight basis. 


\section{Nutritional and dialysis assessment}

Data were collected on a mid-week haemodialysis session before and at the end of the treatment period. BMI was calculated taking into account post-dialysis body weight. Pre-dialysis plasma albumin and transthyretin were measured by immunonephelemetric assays (Behring, Marburg, Germany). Urea and creatinine were measured using conventional methods before and after dialysis in order to determine nPCR, Kt/V urea and Kt/V creatinine (Garred et al. 1997).

\section{Plasma lipids}

Cholesterol, triacylglycerols and phospholipids were measured by enzymatic methods (Roche Diagnostics, Mannheim, Germany) adapted to Hitachi 747 automatic analyser. HDLcholesterol was determined by direct method (Roche Diagnostics) and LDL-cholesterol was calculated by the Friedewald formula (Friedewald et al. 1972). Apo A-I, B, E and lipoprotein (a) were measured by immunonephelemetry (BN100; Dade-Behring Marburg, Marburg, Germany). Apo CII was measured with ApoCII-Auto.N Daïchi kit (Daïchi Pure Chemicals Co., Tokyo, Japan). Apo C-III was determined by an electroimmunodiffusion technique from Laurell (Sebia, Issy-les-Moulineaux, France).

\section{Oxidative stress markers}

Plasma vitamin E was determined by HPLC (Cristol et al. 1997), selenium according to Walther et al. (2000), glutathione peroxidase according to Paglia \& Valentine (1967), plasma advanced oxidation protein products according to Witko-Sarsat et al. (1996) and malondialdehyde by the Yagi method (Yagi, 1976) as adapted in the laboratory (Cristol et al. 1997).

\section{Inflammatory and immune parameters}

C-reactive protein and orosomucoid (or $\alpha 1$-acid glycoprotein) were measured by rate nephelometry using a Beckman Array System protein analyser (Beckman Coulter, Krefeld, Germany). Cytokine concentrations (IL-1, IL-2, IL-6, IL-10, TNF- $\alpha$ and IL- 1 ra) were measured in duplicate by ELISA (R\&D Systems, Lille, France).

\section{Safety assessment}

Vital signs, frequency and seriousness of adverse events and routine laboratory parameters were collected during each dialysis session. Liver function tests were assessed on days 0,15 and 35 .

\section{Statistics}

All parameters were analysed using Statistical Analysis Systems statistical software package version 6.12 (SAS Institute, Cary, NC, USA). Results are expressed as means with their standard errors. Level of significance was set at $P \leq 0 \cdot 05$. Changes in the studied parameters, observed from day 0 to day 35 within each group, were tested using paired- $t$ or Wilcoxon signed-rank tests, according to data distribution.
Similarly, differences between the effects of IDPN observed in the two groups at day 35 were tested using Student's $t$ or Wilcoxon rank-sum tests.

\section{Ethics}

The procedures used in the present study were in accordance with the Helsinki Declaration of 1975 as revised in 1983. The study protocol was approved by the Ethics Committee of Marseilles-2 University. Informed written consent was obtained from all patients.

\section{Results}

On day 0, the two groups presented with comparable nutritional (Table 2), dialysis (Table 2), lipid (Table 3), oxidative (Table 4), inflammatory and immune (Table 5) data. Low predialysis serum concentrations of albumin, transthyretin and creatinine attested for the severity of malnutrition and $\mathrm{Kt} / \mathrm{V}$ values for the adequacy of haemodialysis (Table 2). Parenteral intakes were similar in the two groups (OO v. SO): fat $(\mathrm{g} / \mathrm{kg}$ per dialysis) 0.69 (SEM 0.03) v. 0.73 (SEM 0.02), nitrogen (g/ $\mathrm{kg}$ per dialysis) $0 \cdot 11$ (SEM 0.01) v. $0 \cdot 12$ (SEM 0.01), non-protein energy (kJ/kg per dialysis) 57.45 (SEM 2.43) v. 60.67 (SEM 1.72). Such a nutritional support corresponded to a mean daily supplementation of approximately $0.3 \mathrm{~g}$ protein and $25 \mathrm{~kJ} / \mathrm{kg}(6 \mathrm{kcal} / \mathrm{kg})$.

\section{Evolution from day 0 to day 35 within each group}

Nutritional and dialysis parameters. As shown in Table 2, BMI did not change during the treatment period in $\mathrm{OO}$ as in the SO group. Serum albumin and nPCR increased in both groups while transthyretin and creatinine increased in the SO group. In both groups, Kt/V urea significantly increased from day 0 to day 35 while $\mathrm{Kt} / \mathrm{V}$ creatinine was unchanged.

Plasma lipids. During IDPN, OO and SO patients exhibited an increase in plasma total cholesterol while triacylglycerols and phospholipids were unaffected (Table 3). HDL-cholesterol decreased in the OO group while LDL-cholesterol increased in both groups (Table 3). Apo A-I increased in the SO group and apo B, C-II and C-III in both groups. Apo C-II/apo C-III ratio was not modified by both IDPN regimens. SO patients were characterized by an increase in apo $\mathrm{E}$ and a decrease in lipoprotein (a).

Oxidative stress markers. Among the tested parameters, the only significant changes were an increase in $\alpha$-tocopherol and $\alpha$-tocopherol/cholesterol ratio in $\mathrm{OO}$ group and, in both groups, a decrease in malondialdehyde (Table 4).

Inflammatory and immune parameters. Serum C-reactive protein and orosumucoid were unaffected by IDPN. The increase in lymphocyte count, observed in both groups, did not reach significance (Table 5). Plasma concentration of TNF- $\alpha$ significantly rose in the OO group only. A 3-4-fold increase in IL-2 was observed in both groups.

Comparison of the effects of intradialytic parenteral nutrition between the two groups

The comparison of the effects of OO and SO IDPN on nutritional and dialysis parameters did not show any significant 
Table 2. Nutritional and dialysis parameters*

\begin{tabular}{|c|c|c|c|c|c|c|c|c|c|c|c|c|}
\hline & \multicolumn{5}{|c|}{ Olive oil-based IDPN (OO) } & \multicolumn{5}{|c|}{ Soybean oil-based IDPN (SO) } & & \\
\hline & \multicolumn{2}{|c|}{ Day 0} & \multicolumn{2}{|c|}{ Day 35} & \multirow[b]{2}{*}{ Paired tests } & \multicolumn{2}{|c|}{ Day 0} & \multicolumn{2}{|c|}{ Day 35} & \multirow[b]{2}{*}{ Paired tests } & \multicolumn{2}{|c|}{$\mathrm{OO}$ v. SO } \\
\hline & Mean & SD & Mean & SD & & Mean & SD & Mean & SD & & Day 0 & $\Delta \mathrm{D} 0-\mathrm{D} 35$ \\
\hline BMI & $24 \cdot 6$ & 1.4 & $24 \cdot 7$ & 1.4 & NS & $21 \cdot 6$ & 1.0 & 21.5 & $1 \cdot 0$ & NS & NS & $P<0.05$ \\
\hline Serum albumin (g/l) & 33.5 & 0.9 & $35 \cdot 1$ & 0.8 & $P<0.01$ & $34 \cdot 3$ & 0.7 & $36 \cdot 2$ & 0.9 & $P<0.01$ & NS & NS \\
\hline Serum transthyretin (mg/l) & 254 & 15 & 259 & 17 & NS & 231 & 14 & 254 & 16 & $P<0.05$ & NS & NS \\
\hline $\begin{array}{l}\mathrm{nPCR}(\mathrm{g} / \mathrm{kg} \text { body } \\
\text { weight per } \mathrm{d})\end{array}$ & 1.04 & 0.09 & $1 \cdot 23$ & 0.07 & $P<0.01$ & 0.91 & 0.08 & $1 \cdot 16$ & 0.07 & $P<0.01$ & NS & NS \\
\hline $\mathrm{Kt} / \mathrm{V}$ creatinine & $1 \cdot 16$ & 0.05 & $1 \cdot 12$ & 0.07 & NS & $1 \cdot 15$ & 0.06 & $1 \cdot 17$ & 0.05 & NS & NS & NS \\
\hline $\mathrm{Kt} / \mathrm{V}$ urea & 1.37 & 0.08 & 1.57 & 0.09 & $P<0.01$ & 1.40 & 0.11 & $1 \cdot 72$ & 0.09 & $P<0.01$ & NS & NS \\
\hline
\end{tabular}

IDPN, intradialytic parenteral nutrition; $\mathrm{nPCR}$, normalized protein catabolism rates; $\triangle \mathrm{D} 0-\mathrm{D} 35$, changes over time from day 0 to day 35 .

${ }^{*}$ For details of procedures, see p. 153. For each group of patients randomized to receive IDPN with either olive or with soybean oil-based lipid emulsions, comparisons made on changes from day 0 to the end of the comparative study period (day 35) were tested using paired $t$-test or Wilcoxon signed-rank test. Comparison between the two groups: differences at baseline (day 0$)$ and changes over time ( $\triangle \mathrm{D} 0-\mathrm{D} 35)$ were tested using $t$-test or Wilcoxon rank-sum test. Differences are significant when $P \leq 0.05$.

Table 3. Plasma lipids*

\begin{tabular}{|c|c|c|c|c|c|c|c|c|c|c|c|c|}
\hline & \multicolumn{5}{|c|}{ Olive oil-based IDPN (OO) } & \multicolumn{5}{|c|}{ Soybean oil-based IDPN (SO) } & & \\
\hline & \multicolumn{2}{|c|}{ Day 0} & \multicolumn{2}{|c|}{ Day 35} & \multirow[b]{2}{*}{ Paired tests } & \multicolumn{2}{|c|}{ Day 0} & \multicolumn{2}{|c|}{ Day 35} & \multirow[b]{2}{*}{ Paired tests } & \multicolumn{2}{|c|}{$\mathrm{OO}$ v. SO } \\
\hline & Mean & SD & Mean & SD & & Mean & SD & Mean & SD & & Day 0 & $\Delta \mathrm{D} 0-\mathrm{D} 35$ \\
\hline Cholesterol (mmol/l) & $4 \cdot 82$ & 0.34 & $5 \cdot 13$ & 0.38 & $P<0.05$ & 4.57 & 0.25 & $4 \cdot 88$ & 0.30 & $P<0.05$ & NS & NS \\
\hline Triacylglycerols (mmol/l) & $1 \cdot 86$ & 0.24 & $2 \cdot 23$ & 0.30 & NS & 1.33 & 0.15 & 1.48 & 0.15 & NS & NS & NS \\
\hline Phospholipids (mmol/l) & 2.92 & 0.14 & 2.98 & 0.15 & NS & $2 \cdot 76$ & 0.10 & $2 \cdot 84$ & 0.12 & NS & NS & NS \\
\hline LDL-cholesterol (mmol/l) & 2.94 & 0.32 & 3.17 & 0.37 & $P<0.05$ & $2 \cdot 87$ & 0.22 & $3 \cdot 13$ & 0.26 & $P<0.05$ & NS & NS \\
\hline Apo A-I (g/l) & $1 \cdot 23$ & 0.05 & $1 \cdot 25$ & 0.05 & NS & $1 \cdot 19$ & 0.05 & 1.27 & 0.06 & $P<0.05$ & NS & NS \\
\hline Apo A-II (mg/l) & 266 & 11 & 255 & 10 & NS & 257 & 13 & 256 & 13 & NS & NS & NS \\
\hline Apo B (g/l) & 0.94 & 0.09 & 1.06 & 0.10 & $P<0.01$ & 0.87 & 0.06 & 0.97 & 0.07 & $P<0.01$ & NS & NS \\
\hline Apo C-II (mg/l) & $46 \cdot 6$ & $5 \cdot 7$ & $56 \cdot 0$ & $6 \cdot 4$ & $P<0.01$ & $45 \cdot 9$ & $5 \cdot 2$ & 53.5 & $6 \cdot 5$ & $P<0.05$ & NS & NS \\
\hline Apo C-III (mg/l) & 41.6 & $4 \cdot 3$ & $47 \cdot 9$ & $4 \cdot 7$ & $P<0.01$ & $37 \cdot 0$ & $2 \cdot 8$ & 41.5 & 3.5 & $P<0.05$ & NS & NS \\
\hline Apo CII/C-III & $1 \cdot 11$ & 0.05 & $1 \cdot 16$ & 0.06 & NS & $1 \cdot 23$ & 0.09 & $1 \cdot 27$ & 0.08 & NS & NS & NS \\
\hline Apo E (mg/l) & $47 \cdot 3$ & $4 \cdot 4$ & $51 \cdot 0$ & $4 \cdot 0$ & NS & $46 \cdot 5$ & 6.5 & $53 \cdot 0$ & 3.4 & $P<0.01$ & NS & NS \\
\hline Lipoprotein (a) (g/l) & 0.33 & 0.06 & 0.35 & 0.08 & NS & 0.24 & 0.04 & 0.19 & 0.03 & $P<0.01$ & NS & $P<0.05$ \\
\hline
\end{tabular}

IDPN, intradialytic parenteral nutrition; $\triangle \mathrm{D} 0-\mathrm{D} 35$, changes over time from day 0 to day 35.

${ }^{*}$ For details of procedures, see p. 153. For each group of patients randomized to receive IDPN with either olive or with soybean oil-based lipid emulsions, comparisons made on changes from day 0 to the end of the comparative study period (day 35) were tested using paired $t$-test or Wilcoxon signed-rank test. Comparison between the two groups: differences at baseline (day 0$)$ and changes over time ( $\triangle \mathrm{D} 0-\mathrm{D} 35)$ were tested using $t$-test or Wilcoxon rank-sum test. Differences are significant when $P \leq 0.05$.

Table 4. Parameters of oxidative status*

\begin{tabular}{|c|c|c|c|c|c|c|c|c|c|c|c|c|}
\hline & \multicolumn{5}{|c|}{ Olive oil-based IDPN (OO) } & \multicolumn{5}{|c|}{ Soybean oil-based IDPN (SO) } & & \\
\hline & \multicolumn{2}{|c|}{ Day 0} & \multicolumn{2}{|c|}{ Day 35} & Paired tests & \multicolumn{2}{|c|}{ Day 0} & \multicolumn{2}{|c|}{ Day 35} & Paired tests & \multicolumn{2}{|c|}{$\mathrm{OO}$ v. SO } \\
\hline Retinol $(\mu \mathrm{mol} / \mathrm{l})$ & 3.01 & 0.43 & $3 \cdot 30$ & 0.37 & NS & $2 \cdot 85$ & 0.38 & $3 \cdot 11$ & 0.35 & NS & NS & NS \\
\hline$\alpha$-Tocopherol $(\mu \mathrm{mol} / \mathrm{l})$ & $25 \cdot 14$ & 2.08 & 29.85 & 2.85 & $P<0.05$ & 23.53 & 1.56 & $25 \cdot 02$ & $1 \cdot 71$ & NS & NS & NS \\
\hline $\begin{array}{l}\alpha \text {-Tocopherol/cholesterol } \\
(\mu \mathrm{mol} / \mathrm{mmol} \text { per I) }\end{array}$ & $5 \cdot 30$ & 0.31 & $6 \cdot 17$ & 0.36 & $P<0.01$ & $5 \cdot 13$ & 0.22 & $5 \cdot 34$ & 0.29 & NS & NS & $P<0.05$ \\
\hline Selenium (nmol/l) & 568 & 85 & 445 & 63 & NS & 535 & 68 & 551 & 60 & NS & NS & NS \\
\hline Malondialdehyde $(\mu \mathrm{mol} / \mathrm{l})$ & 696 & 19 & 511 & 35 & $P<0.01$ & 793 & 44 & 532 & 32 & $P<0.01$ & NS & NS \\
\hline $\begin{array}{l}\text { Advanced oxidation protein } \\
\text { products }(\mu \mathrm{mol} / \mathrm{l})\end{array}$ & $43 \cdot 0$ & $3 \cdot 3$ & $50 \cdot 6$ & $5 \cdot 4$ & NS & $42 \cdot 1$ & 3.6 & 43.66 & $3 \cdot 15$ & NS & NS & NS \\
\hline Glutathione peroxidase (U/I) & $193 \cdot 7$ & $12 \cdot 3$ & $205 \cdot 4$ & $15 \cdot 3$ & NS & $224 \cdot 4$ & $17 \cdot 9$ & $210 \cdot 1$ & $18 \cdot 6$ & NS & NS & NS \\
\hline
\end{tabular}

IDPN, intradialytic parenteral nutrition; $\triangle \mathrm{D} 0-\mathrm{D} 35$, changes over time from day 0 to day 35.

${ }^{*}$ For details of procedures, see p. 153. For each group of patients randomized to receive IDPN with either olive or with soybean oil-based lipid emulsions, comparisons made on changes from day 0 to the end of the comparative study period (day 35) were tested using paired $t$-test or Wilcoxon signed-rank test. Comparison between the two groups: differences at baseline (day 0$)$ and changes over time ( $\triangle \mathrm{D} 0-\mathrm{D} 35)$ were tested using $t$-test or Wilcoxon rank-sum test. Differences are significant when $P \leq 0.05$. 


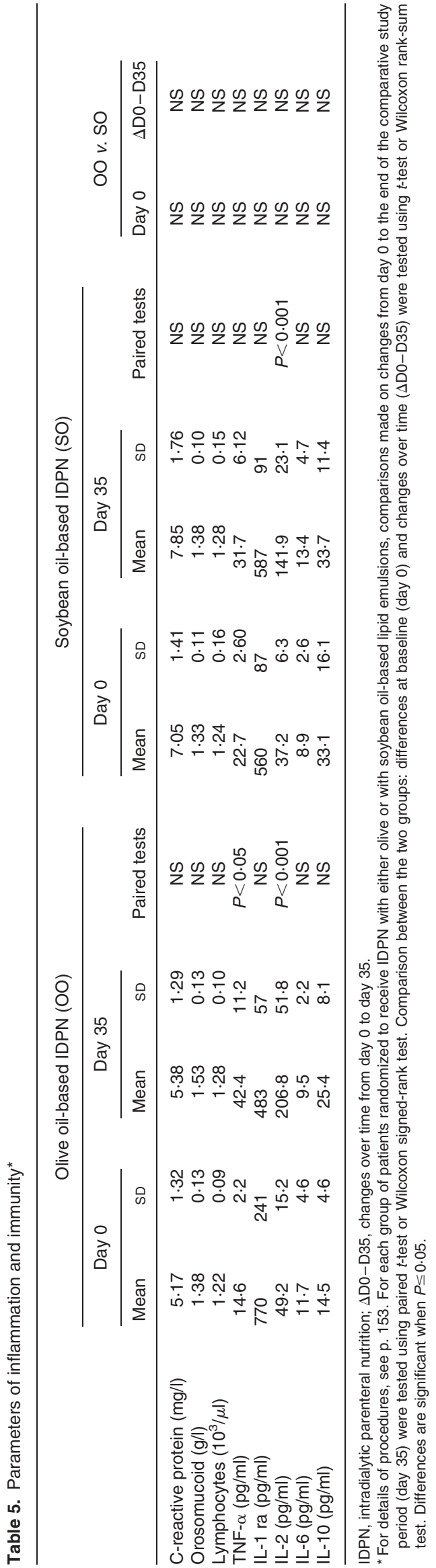

difference except for the variation of BMI from day 0 to day 35 which was increased in $\mathrm{OO}$ as compared to SO patients. The two types of IDPN similarly influenced plasma lipids except for lipoprotein (a) which decreased in the SO group (Table 3). The effects of IDPN on the parameters of oxidative status were similar in the two groups except for the increase in $\alpha$-tocopherol/cholesterol ratio, which was higher in the $\mathrm{OO}$ group (Table 4). No inter-group difference was observed for inflammatory and immune parameters.

\section{Safety of intradialytic parenteral nutrition}

No serious adverse effect was observed in the forty-one patients who received IDPN. Minor adverse events occurred under treatment in seventeen of the twenty-one patients in the OO group and sixteen of the twenty patients in the SO group. The following events were noted: hypotension episode in thirteen patients, nausea in eleven, cramps in ten, vomiting in five and other in four. The frequency of these events was similar in the two groups. Adverse effects were responsible for consent withdrawal in six patients, four receiving the olive oil-based IDPN and two given the soybean oil-based IDPN. Pre-dialysis blood cell count, plasma glucose and liver function tests were unaffected by the two types of IDPN.

\section{Discussion}

It can be estimated from the literature that malnourished haemodialysis patients are characterized by yearly mortality rates reaching approximately 25-30\% (Capelli et al. 1994; Chertow et al. 1994; Combe et al. 2001). As compared with recommended energy and protein supplies, respectively $145 \mathrm{~kJ}(35 \mathrm{kcal})$ and $1.2 \mathrm{~g} / \mathrm{kg}$ per d (National Kidney Foundation, 2000; Toigo et al. 2000), estimated nutritional intakes in malnourished haemodialysis are close to $105 \mathrm{~kJ}(25 \mathrm{kcal})$ and $0.8-1 \mathrm{~g}$ protein $/ \mathrm{kg}$ per $\mathrm{d}$. Among the ways of nutritional supplementation, IDPN is widely used (Chertow et al. 1994) because it is considered to be easy to perform and is usually well tolerated (Wolfson \& Foulks, 1996). Energy supply during IDPN is usually given as glucose-ILE mixtures. However, although haemodialysis patients are characterized by a decrease in triacylglycerol turnover leading to the accumulation of circulating low-molecular weight lipid particles, only one study extensively addressed the effects on plasma lipids of a 1-month intradialytic infusion of a soybean oilbased ILE (Cano et al. 1994). Moreover, the effects of fat emulsion infusion on oxidative, inflammatory and immune status have never been investigated in haemodialysis patients. Therefore, it appeared of interest to look for the impact of two types of IDPN differing by their fatty acid content on nutritional parameters, plasma lipids and markers of oxidative, inflammatory and immune status. As compared with soybean oil-based emulsions, the olive oil-based emulsion used in the present study is characterized by its lower content in PUFA and $n-6$ fatty acids, and higher content of MUFA and $\alpha$-tocopherol (Table 1). The two types of ILE were previously shown to be similar in terms of oxidation rates and tolerance in healthy volunteers and in non-renal malnourished patients (Goulet et al. 1999; Siderova et al. 1993). The use of olive oil-based, as compared to soybean oil-based fat emulsions, 
was reported to be associated with a lower peroxidation index in malnourished children (Goulet et al. 1999).

An improvement of nutritional status has been reported after 3-12 months of IDPN in cohort studies (Snyder et al. 1991; Smolle et al. 1995; Blondin \& Ryan, 1999; Mortelmans et al. 1999; Czekalski \& Hozejowski, 2004), non-controlled comparative studies (Capelli et al. 1994; Chertow et al. 1994; Hiroshige et al. 1998; Piraino et al. 1981) and randomized trials (Cano et al. 1990; Navarro et al. 2000). In the present study, a similar picture was observed after a 5-week IDPN, attesting to the efficacy of this way of nutritional supplementation: although nutritional parameters did not reach normal values during the 5-week observation period, serum albumin significantly increased in the $\mathrm{OO}$ group and serum albumin, transthyretin and predialysis creatinine significantly increased in the SO group. A decrease of delivered $\mathrm{Kt} / \mathrm{V}$ urea has been reported during IDPN (McCann et al. 1999). In the present study, Kt/V urea increased during the 5-week IDPN in the two groups of patients. Because the reliability of $\mathrm{Kt} / \mathrm{V}$ urea measurement may be compromised by the infusion of amino acids and the subsequent rise in urea generation, we also evaluated the efficacy of haemodialysis by measuring creatinine elimination: $\mathrm{Kt} / \mathrm{V}$ creatinine was unaffected from day 0 to day 35 in both groups of patients showing that fat containing IDPN did not alter the efficacy of haemodialysis.

After a 3-month IDPN composed of $31 \mathrm{~g}$ amino acids and $500 \mathrm{ml} 20 \%$ soybean oil-based fat emulsion, plasma cholesterol, triacylglycerols and phospholipids were reported to be unaffected while apo A-I increased (Cano et al. 1990). It was further observed that the intradialytic infusion of a similar fat load during 1 month, without amino acid supply, did not modify plasma cholesterol, triacylglycerols, phospholipids, HDL- and LDL-cholesterol (Cano et al. 1994) and induced an increase in apo B $(+18 \%)$ and apoC-II $(+280 \%)$ together with a decrease in A-I-containing lipoprotein $(-23 \%)$ and lipoprotein (a) $(-30 \%)$. In the present study, fat load was $50 \%$ lower. Plasma cholesterol and LDL-cholesterol slightly but significantly increased during the two types of IDPN while HDL-cholesterol slightly decreased in the OO group. The apo B increase observed in the two groups suggests an activation of liver triacylglycerol metabolism and VLDL secretion. Apo C-II, a cofactor stimulating lipoprotein lipase activity, increased by approximately $20 \%$ in both groups, suggesting that the plasma concentrations of this apo may be similarly influenced by fat load. Apo A-I slightly increased in both groups, this increase reaching significance in the SO group only. Such an increase in apo A-I, observed in amino acid-containing IDPN but not during isolated lipid infusion, suggests that this plasma protein is sensitive to nitrogen supply in haemodialysis patients as described in other conditions (Chavance et al. 1986). The decrease in plasma concentrations of lipoprotein (a) during SO IDPN confirms our previous observations (Cano et al. 1994) and suggests that, as described for $n-3$ fatty acids (Simopoulos, 1991), soybean oil emulsions may be able to lessen plasma lipoprotein (a). To our knowledge, the mechanism of the soybean oil effect on plasma lipoprotein (a) remains unknown.

As expected in these patients, parameters of oxidative status showed a pro-oxidant state on day 0 . The $30 \%$ decrease in malondialdehyde observed during lipid infusion may be explained by the stimulation of fatty acid metabolism and, subsequently, by a reduction of their exposition to oxidative process. $\alpha$-Tocopherol plasma concentration and $\alpha$-tocopherol/cholesterol ratio increased in patients receiving the olive oil-based ILE, suggesting achievement of a somewhat better anti-oxidative status. Due to abnormal metabolism of transthyretin-retinol binding protein-retinol complex (Cano et al. 1988), plasma retinol was elevated in all patients and unaffected by IDPN. Similarly, in spite of the unsaturated fatty acid load, other parameters of oxidative status were not modified.

A uniform increase in plasma concentrations of inflammatory cytokines has been reported in haemodialysis patients (Kimmel et al. 1998; Zwolinska et al. 2000; Hung et al. 2003). The same picture was observed in the present study. During olive oil-based fat emulsion infusion, the decrease in plasma IL-1 ra did not reach significance $(P<0 \cdot 10)$. IL-6 and IL-10 were unaffected by IDPN. Malnutrition is associated with a depression of $\mathrm{TNF}-\alpha$ production by immune cells (Anstead et al. 2003). In haemodialysis patients, plasma TNF- $\alpha$ has been recently reported to be dependent on nutrient supply (Hung et al. 2003). Such a dependence of TNF- $\alpha$ on nutritional supply was confirmed in the present study: TNF- $\alpha$ increased during refeeding in the two groups, its increment being significant in the OO group only. IL-2 production and serum concentrations are related to nutritional status. In man, acute starvation was shown to induce a decrease in IL-2 production from cultured peripheral blood mononuclear cells (Savendahl \& Underwood, 1997). Similarly, decreased IL-2 production and serum concentrations were reported in malnourished patients (Duane et al. 1991; Bessler et al. 1993; Rosenthal, 1999). Conversely, refeeding can prevent the suppression of mesenteric lymph node T-cell proliferation and IL-2 production in burned rats (Choudhry et al. 2003). In haemodialysis patients compared to controls, a $35 \%$ rise of serum IL-2 has been reported, the increase of serum IL-2 during a 3-year follow-up being associated with an improved survival (Kimmel et al. 1998). In the present study, IDPN induced a $400 \%$ increase in serum IL-2 independent of its lipid component, suggesting that protein energy supply was responsible for an increased production of IL- 2 . The suppression of the renal IL-2 degradation in haemodialysis patients likely explained both elevated serum IL-2 at basal state and the magnitude of its increase during refeeding (Ohnishi et al. 1990). Thus, in the present study, olive, similarly to soybean oil-based IDPN, did not adversely affect inflammatory status as estimated by C-reactive protein, orosomucoid and serum cytokines.

The high frequency of minor clinical adverse effects noted in the present series requires some comments. First, the present study is the first to look systematically for any clinically detectable manifestation during the treatment period. Secondly, minor adverse effects such as cramps, hypotension and nausea are commonly observed during dialysis sessions in patients with poor nutritional status not on IDPN. Therefore, it seems likely that these effects were most often not related to IDPN. Finally, adverse events were similar in the two groups suggesting that the safety of the olive oil-based ILE was similar to that of the soybean oil-based ILE.

Present data showed that a 5-week IDPN containing glucose, amino acids and olive oil-based fat emulsion, as compared to a standard soybean oil-based ILE, resulted in a 
similar effect on nutritional status. The effects of the two types of IDPN on plasma lipids and lipoproteins were not different except for the decrease in lipoprotein (a) which was only observed after soybean oil administration. No adverse change in oxidative status was observed during the 5-week observation period in the two groups, the two types of IDPN only differing by an increase in $\alpha$-tocopherol in patients given olive oil-based fat emulsion. Changes in cytokine profile during IDPN were similar in the two groups of patients and only reflected the effect of refeeding on TNF- $\alpha$ and IL-2 synthesis. In this short-term study, the two types of IDPN appeared to be able to improve nutritional status without serious adverse effects. Long-term studies are required to assess possible differences concerning their effect on plasma lipids and indicators of inflammation or oxidative stress.

\section{Acknowledgements}

Noël J. M. Cano wrote the manuscript and conceived the study protocol together with Anne-Marie Dupuy, Henri Portugal, Denis Lairon, Jean-Paul Cristol, Philippe Atlan and Xavier M. Leverve. Yannick Saingra and Adrien Come were responsible for the practical application of the protocol, safety assessment and collection of data, Anne-Marie Dupuy and Jean-Paul Cristol for immune and oxidative parameter assessment, Anne-Marie Lorec-Penet, Henri Portugal and Denis Lairon for lipid parameters. Alexia Le Brun performed the statistical analysis. This work was supported by Baxter SAS, Maurepas, France.

\section{References}

Anstead GM, Chandrasekar B, Zhang Q \& Melby PC (2003) Multinutrient undernutrition dysregulates the resident macrophage proinflammatory cytokine network, nuclear factor-kappaB activation, and nitric oxide production. J Leukoc Biol 74, 982-991.

Attman PO, Samuelsson O, Johansson AC, Moberly JB \& Alaupovic P (2003) Dialysis modalities and dyslipidemia. Kidney Int Suppl., $63110-112$.

Bessler H, Karp L, Notti I, Apter A, Tyano S, Djaldetti M \& Weizman R (1993) Cytokine production in anorexia nervosa. Clin Neuropharmacol 16, 237-243.

Blondin J \& Ryan C (1999) Nutritional status: a continuous quality improvement approach. Am J Kidney Dis 33, 198-202.

Cano N, di Costanzo-Dufetel J, Calaf R, Durbec JP, Lacombe P, Pascal S, Stroumza P \& Labastie-Coeyrehourq J (1988) Prealbumin-retins-binding-protein-retinol complex in hemodialysis patients. Am J Clin Nutr 47, 664-667.

Cano N, Fernandez JP, Lacombe P, Lankester M, Pascal S, Defayolle M, Labastie J \& Saingra S (1987) Statistical selection of nutritional parameters in hemodialyzed patients. Kidney Int 32, Suppl. 22, S178-S180

Cano N, Labastie-Coeyrehourcq J, Lacombe P, Stroumza P, di Costanzo-Dufetel J, Durbec JP, Coudray-Lucas C \& Cynober L (1990) Perdialytic parenteral nutrition with lipids and amino-acids in malnourished hemodialysis patients. Am J Clin Nutr 52, 726-730.

Cano N, Luc G, Stroumza P, Lacombe P \& Durbec JP (1994) Serum lipoprotein changes after prolonged Intralipid ${ }^{\circledR}$ infusion in malnourished hemodialysis patients. Clin Nutr 13, 111-115.

Capelli JP, Kushner H, Camiscioli TC, Chen SM \& Torres MA (1994) Effect of intradialytic parenteral nutrition on mortality rates in end-stage renal disease care. Am $J$ Kidney Dis 23, $808-816$.

Chavance M, Labarre C, Bleiberg F, Jacqueson A, Ducimetiere P, Lemonnier D \& Wade S (1986) Thyroxine-binding prealbumin, overnutrition and apolipoprotein A1. Hum Nutr Clin Nutr 40, 359-364.

Chertow GM, Ling J, Lew NL, Lazarus JM \& Lowrie EG (1994) The association of intradialytic parenteral nutrition administration with survival in hemodialysis patients. Am J Kidney Dis 24, 912-920.

Choudhry MA, Haque F, Khan M, Fazal N, Al-Ghoul W, Ravindranath T, Gamelli RL \& Sayeed MM (2003) Enteral nutritional supplementation prevents mesenteric lymph node T-cell suppression in burn injury. Crit Care Med 31, 1764-1770.

Combe C, Chauveau P, Laville M, Fouque D, Azar R, Cano N, Canaud B, Roth H, Leverve X \& Aparicio M (2001) Influence of nutritional factors and hemodialysis adequacy on the survival of 1,610 French patients. Am J Kidney Dis 37, S81-S88.

Cristol JP, Bosc JY, Badiou S, Leblanc M, Lorrho R, Descomps B \& Canaud B (1997) Erythropoietin and oxidative stress in haemodialysis: beneficial effects of vitamin E supplementation. Nephrol Dial Transplant 12, 2312-2317.

Czekalski S \& Hozejowski R (2004) Intradialytic amino acids supplementation in hemodialysis patients with malnutrition: results of a multicenter cohort study. J Ren Nutr 14, 82-88.

Dasgupta A, Kenny MA \& Ahmad S (1990) Abnormal fatty acid profile in chronic hemodialysis patients: possible deficiency of essential fatty acids. Clin Physiol Biochem 8, 238-243.

DeFronzo RA, Alvestrand A, Smith D, Hendler R, Hendler E \& Wahren J (1981) Insulin resistance in uremia. J Clin Invest 67 , 563-568.

Duane PD, Theahon K \& Crabtree JE (1991) The relationship between nutritional status and serum soluble interleukin-2 receptor concentrations in patients with Crohn's disease treated with elemental diet. Clin Nutr 10, 222-227.

Foulks CJ (1994) The effect of intradialytic parenteral nutrition on hospitalization rate and mortality in malnourished hemodialysis patients. J Renal Nutr 4, 5-10.

Friedewald WT, Levy RI \& Frederickson DS (1972) Estimation of the concentration of low density lipoprotein cholesterol in plasma without the use of preparative ultracentrifuge. Clin Chem 18, 499-502.

Garred LJ, Tang W, Barichello DL \& Canaud B (1997) Equations for the calculation of the protein catabolic rate from predialysis and post dialysis urea concentrations and residual renal clearance in stable hemodialysis patients. Blood Purif 15, 157-168.

Goulet O, de Potter S, Antebi H, Driss F, Colomb V, Bereziat G, Alcindor LG, Corriol O, Le Brun A, Dutot G, Forget D, Perennec V \& Ricour C (1999) Long-term efficacy and safety of a new olive oil-based intravenous fat emulsion in pediatric patients: a doubleblind randomized study. Am J Clin Nutr 70, 338-345.

Granato D, Blum S, Rossle C, Le Boucher J, Malnoe A \& Dutot G (2000) Effects of parenteral lipid emulsions with different fatty acid composition on immune cell functions in vitro. JPEN J Parenter Enteral Nutr 24, 113-118.

Heidland A \& Kult J (1975) Long-term effects of essential amino acids supplementation in patients on regular dialysis treatment. Clin Nephrol 3, 234-239.

Held PJ, Brunner F, Odaka M, Garcia JR, Port FK \& Gaylin DS (1990) Five-year survival for end-stage renal disease patients in the United States, Europe, and Japan. Am J Kidney Dis 15, $451-457$.

Hiroshige K, Iwamoto M, Kabashima N, Mutoh Y, Yuu K \& Ohtani A (1998) Prolonged use of intradialysis parenteral nutrition in elderly malnourished chronic haemodialysis patients. Nephrol Dial Transplant 13, 2081-2087.

Hung AM, Chertow GM, Young BS, Carey S \& Johansen KL (2003) Inflammatory markers are unrelated to physical activity, 
performance, and functioning in hemodialysis. Adv Ren Replace Ther 10, 232-240.

Ikizler TA, Wingard RL, Harvell J, Shyr Y \& Hakim RM (1999) Association of morbidity with markers of nutrition and inflammation in chronic hemodialysis patients: a prospective study. Kidney Int 55, 1945-1951.

Kaysen GA (2001) The microinflammatory state in uremia: causes and potential consequences. J Am Soc Nephrol 12, 1549-1557.

Kimmel PL, Phillips TM, Simmens SJ, Peterson RAKL, Weihs KL, Alleyne S, Cruz I, Yanovski JA \& Veis JH (1998) Immunologic function and survival in hemodialysis patients. Kidney Int 54, $236-244$.

Locatelli F, Canaud B, Eckardt KU, Stenvinkel P, Wanner C \& Zoccali C (2003) Oxidative stress in end-stage renal disease: an emerging threat to patient outcome. Nephrol Dial Transplant 18, 1272-1280.

Madigan KM, Olshan A \& Yingling DJ (1990) Effectiveness of intradialytic parenteral nutrition in diabetic patients with end-stage renal disease. J Am Diet Assoc 90, 861-863.

McCann L, Feldman C, Hornberger J, Belanger S, Maru L, Torres M, Tootell F \& Gotch F (1999) Effect of intradialytic parenteral nutrition on delivered Kt/V. Am J Kidney Dis 33, 1131-1135.

Mortelmans AK, Duym P, Vandenbroucke J, De Smet R, Dhondt A, Lesaffer G, Verwimp H \& Vanholder R (1999) Intradialytic parenteral nutrition in malnourished hemodialysis patients: a prospective long-term study. JPEN J Parenter Enteral Nutr 23, 90-95.

Moussa M, Le Boucher J, Garcia J, Tkaczuk J, Ragab J, Dutot G, Ohayon E, Ghisolfi J \& Thouvenot JP (2000) In vivo effects of olive oil-based lipid emulsion on lymphocyte activation in rats. Clin Nutr 19, 49-54.

National Kidney Foundation (2000) Kidney disease outcomes quality initiative. Clinical practice guidelines for nutrition in chronic renal failure. I. Adult guidelines. A. Maintenance dialysis. Am J Kidney Dis 35, Suppl. 2, S17-S55.

Navarro JF, Mora C, Leon C, Martin-Del Rio R, Macia ML, Gallego E, Chahin J, Mendez ML, Rivero A \& Garcia J (2000) Amino acid losses during hemodialysis with polyacrylonitrile membranes: effect of intradialytic amino acid supplementation on plasma amino acid concentrations and nutritional variables in nondiabetic patients. Am J Clin Nutr 71, 765-773.

Oguz Y, Bulucu F \& Vural A (2001) Oral and parenteral essential amino acid therapy in malnourished hemodialysis patients. Nephron 89, 224-227.

Ohnishi H, Lin KM \& Chu TM (1990) Prolongation of serum half-life of interleukin 2 and augmentation of lymphokine-activated killer cell activity by pepstatin in mice. Cancer Res 50, 1107-1112.

Owen WF, Lew NL, Liu Y, Lowrie EG \& Lazarus JM (1993) The urea reduction rate and serum albumin concentration as predictors of mortality in patients undergoing hemodialysis. $N$ Engl $J$ Med 329, $1001-1006$.

Paglia DE \& Valentine WN (1967) Studies on the quantitative and qualitative characterization of erythrocyte glutathione peroxidase. J Lab Clin Med 70, 158-169.
Piraino AJ, Firpo JJ \& Powers DV (1981) Prolonged hyperalimentation in catabolic chronic dialysis therapy patients. JPEN J Parenter Enteral Nutr 5, 463-477.

Qureshi AR, Alvestrand A, Divino-Filho JC, Gutierrez A, Heimburger O, Lindholm B \& Bergstrom J (2002) Inflammation, malnutrition, and cardiac disease as predictors of mortality in hemodialysis patients. J Am Soc Nephrol 13, Suppl. 1, S28-S36.

Rosenthal AJ (1999) Interleukin-2, its receptor and nutrition in older adults: a review. J Nutr Health Aging 3, 182-185.

Savendahl L \& Underwood LE (1997) Decreased interleukin-2 production from cultured peripheral blood mononuclear cells in human acute starvation. $J$ Clin Endocrinol Metab 82, $1177-1180$.

Schneeweiss B, Graninger W, Stockenhuber F, Druml W, Ferenci P, Eichinger S, Grimm G, Laggner AN \& Lenz K (1990) Energy metabolism in acute and chronic renal failure. Am J Clin Nutr 52, 596-601.

Schulman G, Wingard RL, Hutchison RL, Lawrence P \& Hakim RM (1993) The effects of recombinant human growth hormone and intradialytic parenteral nutrition in malnourished hemodialysis patients. Am J Kidney Dis 21, 527-534.

Siderova VS, Carpentier YA, Dahlan W \& Richelle M (1993) Intravascular metabolism of different fatty acids during lipid infusion in man. Clin Nutr 12, 329-336.

Simopoulos AP (1991) Omega-3 fatty acids in health and disease and in growth and development. Am J Clin Nutr 54, 438-463.

Smolle KH, Kaufmann P, Holzer H \& Druml W (1995) Intradialytic parenteral nutrition in malnourished patients on chronic haemodialysis therapy. Nephrol Dial Transplant 10, $1411-1416$.

Snyder S, Bergen C, Sigler MH \& Teehan BP (1991) Intradialytic parenteral nutrition in chronic hemodialysis patients. ASAIO Trans 37, M373-M375.

Toigo G, Aparicio M, Attman P-O, Cano N, Ciancaruso D, Fouque D, Heidland A, Howard P, Teplan V \& Guarnieri G (2000) ESPEN consensus on nutritional treatment of patients with renal insufficiency (Part 2 of 2). Clin Nutr 19, 281-291.

Walther LE, Winnefeld K \& Solch O (2000) Determination of iron, copper, zinc, magnesium and selenium in plasma and erythrocytes in neurosurgical patients. J Trace Elem Med Biol 14, 92-95.

Witko-Sarsat V, Friedlander M, Capeillere-Blandin C, Nguyen-Khoa $\mathrm{T}$, Nguyen AT, Zingraff J, Jungers $\mathrm{P}$ \& Descamps-Latscha B (1996) Advanced oxidation protein products as a novel marker of oxidative stress in uremia. Kidney Int 49, 1304-1313.

Wolfson M \& Foulks CJ (1996) Intradialytic parenteral nutrition: a useful therapy? Nutr Clin Pract 11, 5-11.

Yagi K (1976) A simple fluorometric assay for lipoperoxide in blood plasma. Biochem Med 15, 212-216.

Zwolinska D, Medynska A, Szprynger K \& Szczepanska M (2000) Serum concentration of IL-2, IL-6, TNF-alpha and their soluble receptors in children on maintenance hemodialysis. Nephron 86, $441-446$. 